Article

\title{
Straightforward Design for Phenoxy-Imine Catalytic Activity in Ethylene Polymerization: Theoretical Prediction
}

\author{
Pongsakorn Chasing 1,2, Phornphimon Maitarad ${ }^{1,2, *}$, Hongmin $\mathrm{Wu}^{2}$, Dengsong Zhang ${ }^{2}$, \\ Liyi Shi ${ }^{2}$ and Vinich Promarak ${ }^{1, *}$ \\ 1 School of Molecular Science and Engineering, Vidyasirimedhi Institute of Science and Technology, \\ Rayong 21210, Thailand; pongsakorn.c_s16@vistec.ac.th \\ 2 Research Center of Nanoscience and Technology, Shanghai University, Shanghai 200444, China; \\ whm_hermione@shu.edu.cn (H.W.); dszhang@shu.edu.cn (D.Z.); shiliyi@shu.edu.cn (L.S.) \\ * Correspondence: pmaitarad@shu.edu.cn (P.M.); vinich.p@vistec.ac.th (V.P.)
}

Received: 4 September 2018; Accepted: 25 September 2018; Published: 28 September 2018

\begin{abstract}
The quantitative structure-activity relationship (QSAR) of 18 Ti-phenoxy-imine (FI-Ti)-based catalysts was investigated to clarify the role of the structural properties of the catalysts in polyethylene polymerization activity. The electronic properties of the FI-Ti catalysts were analyzed based on density functional theory with the M06L/6-31G** and LANL2DZ basis functions. The analysis results of the QSAR equation with a genetic algorithm showed that the polyethylene catalytic activity mainly depended on the highest occupied molecular orbital energy level and the total charge of the substituent group on phenylimine ring. The QSAR models showed good predictive ability $\left(R^{2}\right)$ and $R^{2}$ cross validation $\left(R^{2}{ }_{c v}\right)$ values of greater than 0.927 . The design concept is "head-hat", where the hats are the phenoxy-imine substituents, and the heads are the transition metals. Thus, for the newly designed series, the phenoxy-imine substituents still remained, while the Ti metal was replaced by $\mathrm{Zr}$ or Ni transition metals, entitled FI-Zr and FI-Ni, respectively. Consequently, their polyethylene polymerization activities were predicted based on the obtained QSAR of the FI-Ti models, and it is noteworthy that the FI-Ni metallocene catalysts tend to increase the polyethylene catalytic activity more than that of FI-Zr complexes. Therefore, the new designs of the FI-Ni series are proposed as candidate catalysts for polyethylene polymerization, with their predicted activities in the range of $35,000-48,000 \mathrm{~kg}(\mathrm{PE}) / \mathrm{mol}(\mathrm{Cat}.) \cdot \mathrm{MPa} \cdot \mathrm{h}$. This combined density functional theory and QSAR analysis is useful and straightforward for molecular design or catalyst screening, especially in industrial research.
\end{abstract}

Keywords: phenoxy-imine; ethylene polymerization; QSAR; DFT; catalyst design

\section{Introduction}

As an inexpensive material, polyethylene (PE) has drawn significant attention due to its excellent physical properties, such as high mechanical strength, high elasticity and high resistivity towards corrosion, light weightness, and reusability [1-4]. Normally, the polyethylene materials are prepared via the coordination polymerization using different categories of catalysts, among which metallocenes are very promising candidates that provide high activity and selectivity [5-11]. Many experimental and theoretical methodologies show that the structures of the metallocenes determine their macroscopic properties and catalytic behaviors. Understanding these structures can thus lead to the development of new catalysts with improved properties.

Recently, the development of single site olefin polymerization is one of the hot topics in industrial polyolefins. Generally, to improve the polymerization catalytic performance, there are two desirable 
methods: modification of ligands or transition metal substitutions [11-17]. Each fine-tuned ligand unit can offer various structural and electronic properties that influence the catalytic activity $[13,18]$. In particular, phenoxy-imine can efficiently provide a suitable bulky structure for the ethylene polymerization process. The bidentate ligand was successfully studied by Fujita and co-workers through the generation of a bis(phenoxy-imine) transition metal complex [19-24]. The formation of this organic bulky substituent enhances the catalytic activity, thus initiating the polymerization. Therefore, nowadays, many researchers aim to develop efficient catalysts through ligand design and functionality modification [25-29]. In addition, the metal center was also investigated by substitution between early transition metals and late transition metals, such as $\mathrm{Ti}$ and $\mathrm{Ni}$, respectively $[2,5,30,31]$.

Since current technologies offer high efficiency and performance in simulations and calculations, computational studies of catalyst chemistry are becoming more and more applied to clarify phenomena in molecules. Significant polyolefin catalyst research has been adopted in order to understand the molecular details. As with polyolefin Ziegler-Natta catalysts, Ratanasak and co-worker declared that the calculation results could reasonably explain the role of both electric and steric parameters on catalytic activity and stereoselectivity via density functional theory (DFT) calculations [32,33]. Moreover, the group of Ojwach reported the DFT study of transition metal complex catalysts, which justified that the molecular structure directly affected the catalytic activity [2,34]. The theoretical study of polyethylene polymerization via a titanium phenoxy-imine catalyst was further carried out by Nikitin and co-workers [35]. Their DFT calculations showed that both the structural and electronic properties were related to the experimental catalytic activities. The key parameter was the energy band gap of the frontier molecular orbitals, which depended on the active site of the catalyst. By tuning this parameter, it was showed that the structures and type of substituent groups on the ligands had a significant impact on the energy band gap and catalytic performance. Nevertheless, there was still a lack of information regarding the metal center effect, although this was directly positioned at the active site.

The quantitative structure-activity relationship (QSAR) method, an approach for examining the activities of these catalysts in relation to their structures, is widely applied in catalyst research [28,32,36-39]. In particular, this technique can also provide a better explanation of the different types of electronic and steric factors, which not only affect the bond lengths and angles, but also the highest occupied molecular orbital (HOMO) energy, the lowest unoccupied molecular orbital (LUMO) energy, and the atomic charge. As a result, this quantitative analysis can give an effective insight into the efficiency of different catalysts based on their structure and electronic properties. Thus, in this work, the DFT optimization method and QSAR analysis were applied to investigate the electronic descriptors of Ti-phenoxyimine (FI-Ti) metallocene catalysts related to their polyethylene polymerization activity. A genetic algorithm with multiple linear regression (GA-MLR) was selected to derive the QSAR equations [40-43]. Based on the best obtained QSAR equation, it was then used to predict the polyethylene polymerization activity of the newly designed Zr- and Ni-phenoxyimine catalysts.

\section{Results and Discussion}

\subsection{Electronic Properties}

In this work, we studied the relationship between the PE activity and the basic electronic properties of the FI-Ti catalysts. Eighteen FI-Ti catalysts were used as a training set for manipulating the QSAR equation. The structure details of each candidate and their experimental catalyst activity that were collected from Nikitin's work [35] are shown in Table 1 (for more details regarding experimental data, see Materials and Methods). The range of PE catalytic activities (A) was found to be $4100-54,200 \mathrm{~kg}(\mathrm{PE}) / \mathrm{mol}(\mathrm{Cat}$ ). $\mathrm{MPa} \cdot \mathrm{h}$. Therefore, the activities were converted into $\ln (\mathrm{A})$ values (listed in Table 1), which is the same unit as the electronic properties. Based on the QSAR equation, the experimental activity would serve as the dependent variable, while the electronic properties would be independent ones. Thus, all catalysts were built and then optimized using DFT with the 
M06L exchange-correlation functional [44] via the 6-31G $G^{* *}$ and LANL2DZ basis functions. The M06L, an empirical functional, is accurate for noncovalent interactions, main group thermochemistry, and transition metals $[45,46]$. In this work, we applied the M06L functional with 6-31G $\mathrm{G}^{* *}$ for $\mathrm{C}, \mathrm{H}, \mathrm{O}$, $\mathrm{N}$, and $\mathrm{Br}$, and LANL2DZ for Ti, Ni, and $\mathrm{Zr}$. The selection of the M06L functional is based on previous benchmark studies [46-48]. Zhao and Truhlar [46] reported that M06L has reasonably good overall performance, and it is the best functional for transition metal energetics, and for the study of organometallic and inorganometallic thermochemistry. Furthermore, M06L was reported as a good choice for calculations on some small non-covalent dimers in both geometric and electronic studies [47]. In addition, the M06L functional was successfully carried out on dihydropyrazine series annulated linear polyacene systems to study the aromaticity and HOMO-LUMO energy [48].

Table 1. Chemical structure of FI-Ti catalysts with different substituents $\mathbf{R}_{\mathbf{1}}, \mathbf{R}_{\mathbf{2}}$, and $\mathbf{R}_{\mathbf{3}}$ (data cited from reference [35]).

\begin{tabular}{|c|c|c|c|c|c|}
\hline Complex & $\mathbf{R}_{\mathbf{1}}$ & $\mathbf{R}_{2}$ & $\mathbf{R}_{3}$ & $\begin{array}{c}\text { Activity (A) } \\
(\mathrm{kg}(\text { PE)/mol(Cat.) } \cdot \mathrm{MPa} \cdot \mathrm{h})\end{array}$ & $\ln (A)$ \\
\hline $1 \mathrm{Ti}$ & $\mathrm{t}-\mathrm{Bu}$ & $\mathrm{H}$ & $\mathrm{H}$ & 4100 & 3.613 \\
\hline $2 \mathrm{Ti}$ & $\mathrm{t}-\mathrm{Bu}$ & $\mathrm{H}$ & m-OAll & 17,800 & 4.250 \\
\hline $3 \mathrm{Ti}$ & $\mathrm{t}-\mathrm{Bu}$ & $\mathrm{H}$ & $p$-OAll & 54,200 & 4.734 \\
\hline $4 \mathrm{Ti}$ & $\mathrm{t}-\mathrm{Bu}$ & $\mathrm{Me}$ & $\mathrm{H}$ & 17,100 & 4.233 \\
\hline $5 \mathrm{Ti}$ & $\mathrm{t}-\mathrm{Bu}$ & $\mathrm{Me}$ & $m$-OAll & 13,600 & 4.134 \\
\hline $6 \mathrm{Ti}$ & $\mathrm{t}-\mathrm{Bu}$ & $\mathrm{Me}$ & $p$-OAll & 39,000 & 4.591 \\
\hline $7 \mathrm{Ti}$ & $\mathrm{t}-\mathrm{Bu}$ & $\mathrm{t}-\mathrm{Bu}$ & $\mathrm{H}$ & 19,400 & 4.288 \\
\hline $8 \mathrm{Ti}$ & $\mathrm{t}-\mathrm{Bu}$ & $\mathrm{t}-\mathrm{Bu}$ & m-OAll & 12,400 & 4.093 \\
\hline 9Ti & $\mathrm{t}-\mathrm{Bu}$ & $\mathrm{t}-\mathrm{Bu}$ & $p$-OAll & 33,000 & 4.519 \\
\hline $10 \mathrm{Ti}$ & Cumyl & $\mathrm{H}$ & $\mathrm{H}$ & 27,400 & 4.438 \\
\hline $11 \mathrm{Ti}$ & Cumyl & $\mathrm{H}$ & m-OAll & 32,600 & 4.513 \\
\hline $12 \mathrm{Ti}$ & Cumyl & $\mathrm{H}$ & $p$-OAll & 34,500 & 4.538 \\
\hline $13 \mathrm{Ti}$ & Cumyl & $\mathrm{Me}$ & $\mathrm{H}$ & 34,050 & 4.532 \\
\hline $14 \mathrm{Ti}$ & Cumyl & $\mathrm{Me}$ & $m$-OAll & 19,800 & 4.297 \\
\hline $15 \mathrm{Ti}$ & Cumyl & $\mathrm{Me}$ & $p$-OAll & 29,400 & 4.468 \\
\hline $16 \mathrm{Ti}$ & Cumyl & Cumyl & $\mathrm{H}$ & 18,550 & 4.268 \\
\hline $17 \mathrm{Ti}$ & Cumyl & Cumyl & $m$-OAll & 26,000 & 4.415 \\
\hline $18 \mathrm{Ti}$ & Cumyl & Cumyl & $p$-OAll & 25,700 & 4.410 \\
\hline
\end{tabular}

Based on the optimized FI-Ti structures, with consideration of a symmetric skeleton structure of metallocene catalysts (see inserted figure of Table 2), there is only one Ti atom, thus, the partial charge of the Ti atom was collected. Alternatively, a pair of $\mathrm{O}, \mathrm{N}$, and $\mathrm{Cl}$ atoms coordinated to Ti metal; therefore, the charge of $\mathrm{O}, \mathrm{N}$, and $\mathrm{Cl}$ was calculated from the average charge of $\left(\mathrm{e}_{\mathrm{A}}+\mathrm{e}_{\mathrm{B}}\right) / 2$, where the $\mathrm{e}_{\mathrm{A}}$ and $\mathrm{e}_{\mathrm{B}}$ are the partial charge of $\mathrm{O}_{\mathrm{A}}, \mathrm{N}_{\mathrm{A}}$, or $\mathrm{Cl}_{\mathrm{A}}$, and $\mathrm{O}_{\mathrm{B}}, \mathrm{N}_{\mathrm{B}}$, or $\mathrm{Cl}_{\mathrm{B}}$, respectively. For the phenoxy-imine ligands, there are three substituents attached on phenyl rings; $\mathbf{R}_{\mathbf{1}}$ and $\mathbf{R}_{\mathbf{2}}$ were $o$ - and $p$-substitutions on phenoxy ring $\mathbf{I}$, respectively, whereas $\mathbf{R}_{\mathbf{3}}$ was a $m-$, or $p$-substituent on phenylimine ring II. Therefore, to elucidate the electronic effects of ligand substitution, the partial charge of all atoms in each substituent group was combined, which recalled the total charge of the $\mathbf{R}_{\mathbf{1}}, \mathbf{R}_{\mathbf{2}}$ and $\mathbf{R}_{\mathbf{3}}$ groups. However, based on the bis-phenoxyimine structure, there are pairs of $\mathbf{R}_{\mathbf{1}}, \mathbf{R}_{\mathbf{2}}$, and $\mathbf{R}_{\mathbf{3}}$; 
therefore, the electronic charge of ligand substitutions was calculated from $\left(t_{A}+t_{B}\right) / 2$, where $t_{A}$ is the total charge of the $\mathbf{R}_{1 \mathrm{~A}}, \mathbf{R}_{\mathbf{2 A}}$, or $\mathbf{R}_{\mathbf{3 A}}$ group, and $t_{\mathrm{B}}$ is the total charge of the $\mathbf{R}_{\mathbf{1 B}}, \mathbf{R}_{\mathbf{2 B}}$, or $\mathbf{R}_{\mathbf{3 B}}$ group. In addition, the HOMO energy, LUMO energy, and the HOMO-LUMO energy gap (E-gap) were also included, as listed in Table 2.

Table 2. FI-Ti electronic descriptor data.

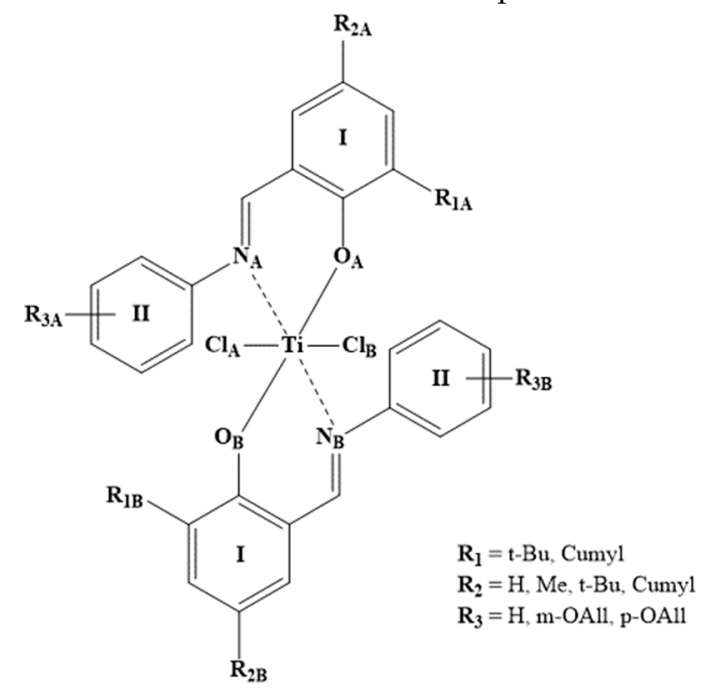

\begin{tabular}{ccccccccccc}
\hline Complex & $\mathbf{T i}^{\mathbf{a}}$ & $\mathbf{O}^{\mathbf{b}}$ & $\mathbf{N}^{\mathbf{b}}$ & $\mathbf{C l}^{\mathbf{b}}$ & $\mathbf{R 1}^{\mathbf{c}}$ & $\mathbf{R 2}^{\mathbf{c}}$ & $\mathbf{R 3}^{\mathbf{c}}$ & HOMO $^{\mathbf{d}}$ & $\mathbf{L U M O}^{\mathbf{d}}$ & $\mathbf{E}^{\mathbf{G}} \mathbf{a p}^{\mathbf{d}}$ \\
\hline $1 \mathrm{Ti}$ & 1.235 & -0.704 & -0.586 & -0.374 & -1.062 & 0.136 & 0.136 & -0.199 & -0.131 & 1.840 \\
$2 \mathrm{Ti}$ & 1.232 & -0.703 & -0.585 & -0.374 & -1.062 & 0.345 & -1.117 & -0.197 & -0.129 & 1.858 \\
$3 \mathrm{Ti}$ & 1.247 & -0.706 & -0.588 & -0.376 & -1.057 & 0.130 & -1.230 & -0.194 & -0.127 & 1.843 \\
$4 \mathrm{Ti}$ & 1.234 & -0.707 & -0.589 & -0.377 & -1.058 & -0.450 & 0.134 & -0.193 & -0.129 & 1.736 \\
$5 \mathrm{Ti}$ & 1.227 & -0.705 & -0.589 & -0.378 & -1.062 & -0.446 & -1.109 & -0.191 & -0.126 & 1.770 \\
$6 \mathrm{Ti}$ & 1.250 & -0.709 & -0.592 & -0.380 & -1.055 & -0.442 & -1.134 & -0.191 & -0.124 & 1.812 \\
$7 \mathrm{Ti}$ & 1.252 & -0.713 & -0.610 & -0.372 & -1.056 & -1.083 & 0.134 & -0.197 & -0.129 & 1.863 \\
$8 \mathrm{Ti}$ & 1.235 & -0.707 & -0.588 & -0.380 & -1.033 & -1.054 & -1.097 & -0.191 & -0.124 & 1.817 \\
$9 \mathrm{Ti}$ & 1.236 & -0.707 & -0.586 & -0.381 & -1.030 & -1.054 & -1.116 & -0.187 & -0.124 & 1.720 \\
$10 \mathrm{Ti}$ & 1.243 & -0.708 & -0.607 & -0.362 & -1.147 & 0.139 & 0.136 & -0.198 & -0.133 & 1.765 \\
$11 \mathrm{Ti}$ & 1.273 & -0.706 & -0.603 & -0.372 & -1.303 & 0.137 & -1.129 & -0.199 & -0.130 & 1.867 \\
$12 \mathrm{Ti}$ & 1.232 & -0.694 & -0.578 & -0.374 & -1.254 & 0.122 & -1.131 & -0.189 & -0.124 & 1.765 \\
$13 \mathrm{Ti}$ & 1.242 & -0.696 & -0.584 & -0.376 & -1.248 & -0.026 & 0.133 & -0.189 & -0.125 & 1.739 \\
$14 \mathrm{Ti}$ & 1.269 & -0.707 & -0.606 & -0.376 & -1.302 & -0.445 & -1.125 & -0.191 & -0.127 & 1.764 \\
$15 \mathrm{Ti}$ & 1.224 & -0.700 & -0.579 & -0.376 & -1.257 & -0.432 & -1.121 & -0.185 & -0.123 & 1.688 \\
$16 \mathrm{Ti}$ & 1.286 & -0.703 & -0.538 & -0.385 & -1.222 & -1.353 & 0.120 & -0.189 & -0.121 & 1.856 \\
$17 \mathrm{Ti}$ & 1.236 & -0.705 & -0.602 & -0.370 & -1.216 & -1.350 & -1.101 & -0.189 & -0.123 & 1.794 \\
$18 \mathrm{Ti}$ & 1.270 & -0.709 & -0.598 & -0.384 & -1.262 & -1.305 & -1.102 & -0.190 & -0.125 & 1.750 \\
\hline
\end{tabular}

${ }^{\mathrm{a}}=$ partial charge $(\mathrm{e}),{ }^{\mathrm{b}}=$ average charge $(\mathrm{e}),{ }^{\mathrm{c}}=$ average of total charge of substituent group $(\mathrm{e}){ }^{\mathrm{d}}=$ in Ha unit.

\subsection{QSAR Model Relationship}

The main steps in the QSAR study were the calculations and selections of structural descriptors as numerical variables representing each chemical structure. Firstly, the $\ln (\mathrm{A})$ activity and all electronic descriptors were calculated, and the pairwise correlation-located correlation coefficient was a number that was a measure of the strength and the direction of the correlation between two variables. It was be expressed using the variable $r$, where $r$ was between 1 and -1 . Thus, the data points with a perfect strength line are $r=-1$ or $r=1$. When $r<0$ or $r>0$, the data would have negative or positive associations, respectively. The obtained correlation coefficients of greater than \pm 0.8 were classified as being intercorrelated, and only one of them with a high correlation with the activity data was considered in developing the model. Based on our correlation matrix in Table 3, the high correlation coefficient was only found on HOMO and LUMO pairwise, with a 0.890 correlation coefficient value. However, both of them resulted in similar correlation coefficients to $\ln (\mathrm{A})$; therefore, these two descriptors would be further selected by the occurrences of the population in the genetic algorithm 
(GA) process. Then, all 10 electronic descriptors were used as input descriptors for manipulating the QSAR equation of the FI-Ti catalysts.

GAs are a well-known and widely employed variable selection method that is used to solve the optimization problems defined by fitness criteria, applying the evolution hypothesis of Darwin and various genetic functions, i.e., cross-over and mutation [49-52]. GAs have been applied in various fields for many applications involving regression problems, and they offer a new approach to the problem of QSAR models. By using the major characteristics of Darwinian evolution, GAs can construct complicated models that not only use linear polynomials, but also higher-order polynomials, splines and Gaussians, allowing for the production of a more widespread model [43,53-57]. Generally, GAs work with a set of strings that are called a population. This population is evolved in such a manner that leads it toward the objective of the search. There are three operations of selection, crossover and mutation, which are iteratively performed, and then newly added members are scored according to a fitness criterion that is related to the quality of the regression fit to the data. Thus, the selection probabilities must be re-evaluated each time a new member is added to the population, and then the convergence is triggered by a lack of progress in the highest and average scores of the population [57]. Therefore, in this work, to select the most relevant descriptors, the evolution of the population was simulated and the occurrences of populations of 10 descriptors are depicted in Figure 1. As the GA population of each parameter was considered to be the basic value of fitness for the QSAR model, it was found that the HOMO energy level exhibits the highest value, followed by the $\mathbf{R}_{3}$ total charge, and then the Ti charge with occurrences in population of 2097, 1067, and 351, respectively, whereas the rest of the descriptors only resulted in a range of 10-67 populations, as shown in Figure 1. This indicates that the FI-Ti catalytic activity is closely related to the HOMO energy level, the $\mathbf{R}_{3}$ total charge, and the Ti charge. Looking into the details of both correlation coefficient and occurrences of populations, we observed that the complex with the lower HOMO energy level combined with the higher negative charge of the $\mathbf{R}_{3}$ substituent group showed the better catalytic activity (see in Table 2). For example, the complex 3Ti with a low HOMO energy of $-0.194 \mathrm{eV}$ and high $\mathbf{R}_{3}$ negative charge of -1.230 achieved the highest PE activity value of $54,200 \mathrm{~kg}(\mathrm{PE}) / \mathrm{mol}(\mathrm{Cat}.) \cdot \mathrm{MPa} \cdot \mathrm{h}$, while complex $\mathbf{1 T i}$ with $\mathbf{R}_{3}$ positive charge gave the lowest catalytic activity of $4100 \mathrm{~kg}(\mathrm{PE}) / \mathrm{mol}(\mathrm{Cat}$.) $\mathrm{MPa} \cdot \mathrm{h}$. Consequently, when the substituents differ, the Ti center atom charge was also affected, and complexes with a Ti charge of $~ 1.24-1.25$ showed higher catalytic activity than the others. Thus, these three descriptors would further be set as independent variables in the QSAR equation investigation.

Table 3. Correlation matrix of polyethylene (PE) activity in term of $\ln (\mathrm{A})$ and 10 electronic properties. High correlations $(\geq \pm 0.8)$ are labelled in gray cells.

\begin{tabular}{|c|c|c|c|c|c|c|c|c|c|c|c|}
\hline Des. & $\ln (A)$ & $\mathrm{Ti}^{\mathrm{a}}$ & $\mathrm{O}^{\mathrm{b}}$ & $\mathbf{N}^{b}$ & $\mathrm{Cl}^{\mathrm{b}}$ & $R 1^{c}$ & $R 2^{c}$ & $R 3^{c}$ & HOMO & LUMO & E-Gap \\
\hline $\ln (\mathrm{A})$ & 1.000 & 0.155 & 0.119 & -0.084 & 0.033 & -0.298 & 0.041 & -0.380 & 0.355 & 0.327 & -0.225 \\
\hline $\mathrm{Ti}^{\mathrm{a}}$ & 0.155 & 1.000 & -0.312 & 0.119 & -0.294 & -0.468 & -0.290 & 0.114 & -0.156 & 0.040 & 0.391 \\
\hline $\mathrm{O}^{\mathrm{b}}$ & 0.119 & -0.312 & 1.000 & 0.175 & -0.003 & -0.268 & 0.027 & -0.169 & 0.449 & 0.296 & -0.472 \\
\hline $\mathrm{N}^{\mathrm{b}}$ & -0.084 & 0.119 & 0.175 & 1.000 & -0.568 & -0.032 & -0.128 & 0.159 & 0.397 & 0.550 & 0.043 \\
\hline $\mathrm{Cl}^{\mathrm{b}}$ & 0.033 & -0.294 & -0.003 & -0.568 & 1.000 & -0.065 & 0.501 & 0.219 & -0.524 & -0.636 & 0.087 \\
\hline $\mathrm{R} 1^{\mathrm{c}}$ & -0.298 & -0.468 & -0.268 & -0.032 & -0.065 & 1.000 & 0.002 & 0.112 & -0.280 & -0.225 & 0.230 \\
\hline $\mathrm{R} 2^{\mathrm{C}}$ & 0.041 & -0.290 & 0.027 & -0.128 & 0.501 & 0.002 & 1.000 & 0.017 & -0.480 & -0.567 & 0.103 \\
\hline $\mathrm{R} 3^{\mathrm{c}}$ & -0.380 & 0.114 & -0.169 & 0.159 & 0.219 & 0.112 & 0.017 & 1.000 & -0.347 & -0.396 & 0.096 \\
\hline HOMO & 0.355 & -0.156 & 0.449 & 0.397 & -0.524 & -0.280 & -0.480 & -0.347 & 1.000 & 0.890 & -0.684 \\
\hline LUMO & 0.327 & 0.040 & 0.296 & 0.550 & -0.636 & -0.225 & -0.567 & -0.396 & 0.890 & 1.000 & -0.275 \\
\hline E-Gap & -0.225 & 0.391 & -0.472 & 0.043 & 0.087 & 0.230 & 0.103 & 0.096 & -0.684 & -0.275 & 1.000 \\
\hline
\end{tabular}

${ }^{\mathrm{a}}=$ partial charge $(\mathrm{e}),{ }^{\mathrm{b}}=$ average charge $(\mathrm{e}){ }^{\mathrm{c}}=$ average of total charge of substituent group (e). 


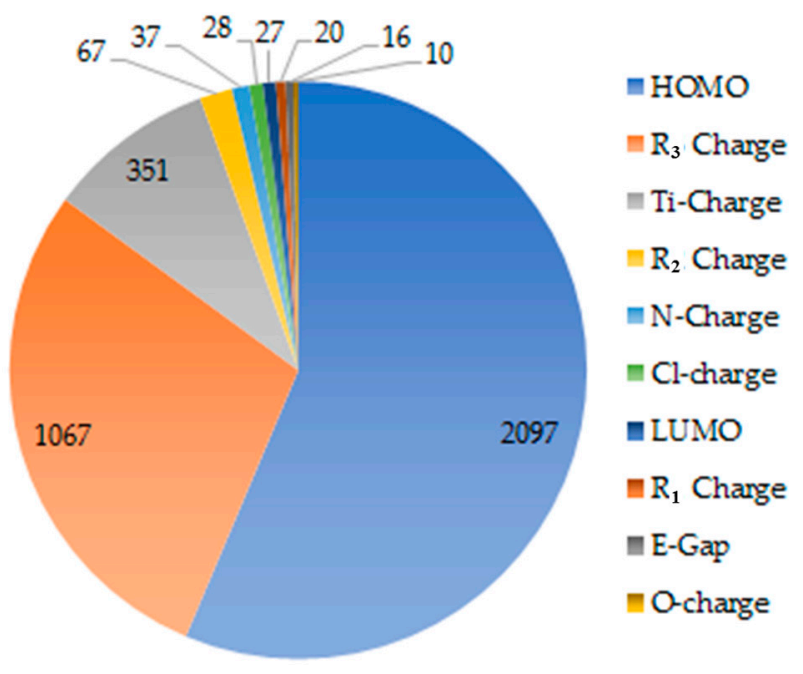

Figure 1. Occurrences of populations of 10 electronic descriptors by the genetic algorithm (GA) method.

From the GA population results, we found the promising parameter candidates for QSAR model construction, then, those three electronic parameters of the HOMO energy level, $\mathbf{R}_{\mathbf{3}}$ total charge and Ti atomic charge were used to generate Equation (1) see Table 4. With consideration of QSAR Equation (1), the linear function was found to describe the relationship between the PE catalytic activity in terms of $\ln (\mathrm{A})$ and three electronic properties, the $\mathbf{R}_{\mathbf{3}}$ charge, HOMO energy, and Ti atomic charge. It consisted of ramp functions that are continuous functions, segmented in three parts: $\mathrm{x}_{\mathrm{fit}}(t)=\mathrm{x}_{1}$ for $t \leq t_{1}, \mathrm{x}_{2}$ for $t \geq t_{2}$, and linearly connected between $t_{1}$ and $t_{2}$. This type of function is very useful and has many applications in engineering and mathematics [58,59]. As shown in Table 4, Equation (1) exhibited an excellent correlation with an $R$-squared $\left(R^{2}\right)$ value of 0.992 . The obtained model also showed a high prediction ability with a cross-validated technique $R$-squared $\left(\mathrm{R}^{2} \mathrm{cv}\right)$ value of 0.936 . In addition, the data distribution was evaluated by the F value, which resulted in 168.295. Although it seems that this model is a good model, the population data of the GA imposed a question on us that Ti charge population was actually very small compared with the other two descriptors. Furthermore, based on the "head-hat" design concept, the Ti center would be replaced with other metals; thus, to avoid the direct effect of the metal's partial charge, the elimination of the Ti charge parameter was suitable to accomplish a better QSAR model.

Table 4. Statistical results of quantitative structure-activity relationship (QSAR) equations on FI-Ti series.

\begin{tabular}{|c|c|c|c|c|}
\hline No & Equation $^{c}$ & $\mathbf{R}^{2}$ & $\mathbf{R}_{\mathrm{cv}}^{2}$ & F Value \\
\hline Equation (1) & $\begin{array}{l}\ln (\text { Activity })=26.09 \times\left(\mathrm{R}_{3} \text { Charge }+0.22\right)-7.47 \times\left(\mathrm{R}_{3}\right. \\
\text { Charge }+1.18)+497.87 \times(\mathrm{HOMO}+0.19)-494.72 \times \\
(\mathrm{HOMO}+0.19)-7.81 \times(1.24-\text { Ti-Charge })+1943.36 \times \\
(-0.20-\text { HOMO })-3345.07 \times(-0.20-\text { HOMO })+4.73\end{array}$ & 0.992 & 0.936 & 168.295 \\
\hline Equation (2) ${ }^{a}$ & $\begin{array}{l}\ln (\text { Activity })=-4.91 \times\left(\mathrm{R}_{3} \text { Charge }+1.22\right)+23.54 \times\left(\mathrm{R}_{3}\right. \\
\text { Charge }+0.13)+33949.84 \times(-0.19-\mathrm{HOMO})-2361.91 \\
\times(-0.20-\mathrm{HOMO})+743.80 \times(-0.20-\mathrm{HOMO})- \\
33941.61 \times(-0.19-\mathrm{HOMO})+5.00\end{array}$ & 0.992 & 0.984 & 230.917 \\
\hline Equation (3) $b$ & $\begin{array}{l}\ln (\text { Activity })=-9.15 \times\left(\mathrm{R}_{3} \text { Charge }+1.17\right)+30.70 \times\left(\mathrm{R}_{3}\right. \\
\text { Charge }+0.24)-257.00 \times(\mathrm{HOMO}+0.189)+225.65 \times \\
(\mathrm{HOMO}+0.19)-1938.84 \times(-0.20-\mathrm{HOMO})+533.89 * \\
(-0.20-\mathrm{HOMO})+4.74\end{array}$ & 0.997 & 0.927 & 564.305 \\
\hline
\end{tabular}

\footnotetext{
${ }^{\mathrm{a}}$ reduced Ti-charge descriptor, ${ }^{\mathrm{b}}$ deleted outliers, ${ }^{\mathrm{c}}$ linearity ramp function equation.
} 


\subsection{QSAR Model Improvement via the Elimination of Insignificant Descriptors and Outliers}

As discussed above, the Ti charge exhibited a significantly lower occurrence population when compared with the two properties in Equation (1). Thus, an elimination of the weak parameter strategy was applied. The two-descriptor models of the HOMO energy levels, and the $\mathbf{R}_{\mathbf{3}}$ total charge was generated. As shown in Table 4, the QSAR Equation (2) still obtained a good predictive ability with an $\mathrm{R}^{2}$ value of 0.992 and rising on $\mathrm{R}^{2}{ }_{\mathrm{cv}}$ of 0.984 . Furthermore, the data distribution $\mathrm{F}$ value of Equation (2) was also increased to 230.917, which was higher than that in Equation (1). It is noteworthy that with only two electronic property variables, the obtained QSAR model resulted in higher reliability and better predictive ability. The analysis results confirmed that the partial Ti atom charge plays a less important role in PE catalytic activity prediction.

Generally, with the exception of the predictive ability, the model with the higher F value was considered to be the better model. Although Equation (2) showed very good correlation and predictable ability, if there were some choices for more accurate predicted results, it would be completed to improve the model. Thus, based on Equation (2), the accuracy was considered via the residual value that was calculated from the experimental and predicted $\ln (\mathrm{A})$ of PE polymerization, as illustrated in Figure 2. The graph shows that there were two outliers exhibiting more than a $|2|$ scaled residual value, which are the complexes $6 \mathrm{Ti}(2.128)$ and $12 \mathrm{Ti}(-2.168)$. These outliers show high residual results for the predicted activity compared to the others, and this reason led to the error of the whole model. Thus, to further improve the QSAR model, the data of 6 Ti and 12Ti complexes were eliminated, and then QSAR Equation (3) was generated. The results indicated that the new model of Equation (3) achieved a superior higher $F$ value of 564.305, which was twice that of the previous one, while still exhibiting high prediction ability with an $R^{2}$ of 0.997 and an $R^{2}{ }_{c v}$ of 0.927 . Therefore, both Equations (2) and (3) were selected to predict the PE activity of FI-Ti catalysts using the GA-MLR of the ramp function, and their graphical plots between the experimental and predicted PE activities are depicted in Figure 3a,b, respectively.

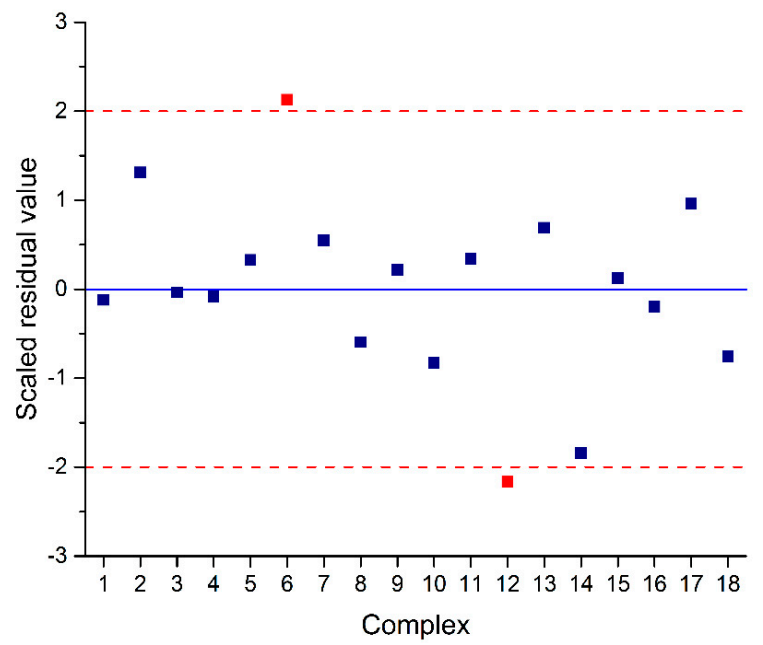

Figure 2. A scaled residual plot of training set obtained from Equation (2) for FI-Ti catalysts. 

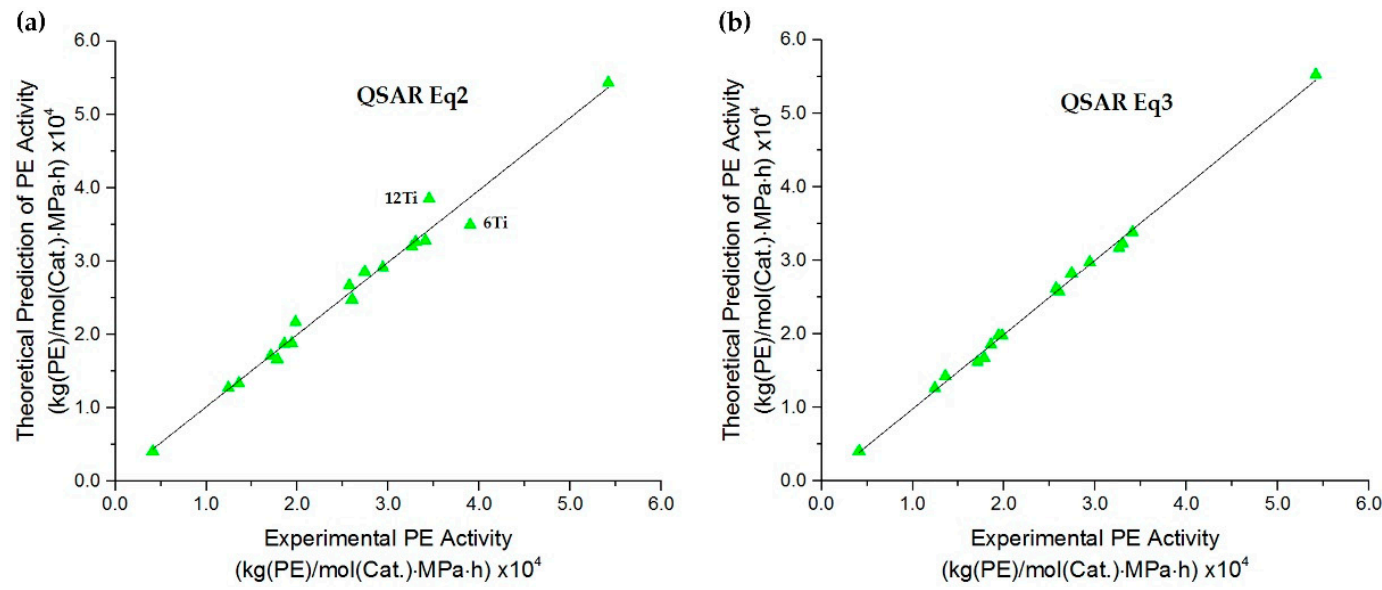

Figure 3. The plot of the experimental PE activities versus the predicted ones obtaining from Equation (2) (a), and Equation (3) (b) for FI-Ti catalysts.

\subsection{Prediction of PE Polymerization Activity for Newly Designed Zr and Ni Phenoxyimine Catalysts}

We propose the design concept of "head-hat", where the hats are phenoxy-imine substituents and the heads are transition metals. In this work, based on the training set of the FI-Ti catalysts, the Ti metal center was then replaced by $\mathrm{Zr}$ or Ni transition metals, while keeping the same phenoxy-imine substituents, namely, the FI-Zr and FI-Ni series, respectively, as shown in Table 5. The new FI-Zr and FI-Ni complex structures were systemically built and optimized using the same criteria as the FI-Ti catalysts. Their HOMO energy levels and $\mathbf{R}_{\mathbf{3}}$ total charges were then extracted. The prediction of the PE activities of the new FI-Zr and FI-Ni catalysts was carried out by applying QSAR model Equations (2) and (3), as listed in Table 5. Furthermore, to investigate the PE polymerization tendency performance, the results of the overall $\mathrm{PE}$ catalytic activities versus the $\mathrm{Ti}, \mathrm{Zr}$, and Ni phenoxy-imine complexes were plotted using Equations (2) and (3), as depicted in Figure 4a,b, respectively. Based on the graphical plots, the trend of higher PE activity was found to follow the order of FI-Ni > FI-Ti > FI-Zr, which agreed well with both QSAR Equations (2) and (3).

In Table 5, assuming the purposed metallocenes for PE catalysts could obtain the theoretical PE activities prediction of higher than $35,000 \mathrm{~kg}(\mathrm{PE}) / \mathrm{mol}(\mathrm{Cat}.) \cdot \mathrm{MPa} \cdot \mathrm{h}$. Thus, an insight into the details of predicted PE activities for the FI-Zr and FI-Ni series based on Equation (2) consisted of $7 \mathbf{Z r}, 2 \mathrm{Ni}$, $3 \mathrm{Ni}, 4 \mathrm{Ni}, 6 \mathrm{Ni}, 7 \mathrm{Ni}, 10 \mathrm{Ni}, 12 \mathrm{Ni}, 13 \mathrm{Ni}$, and $15 \mathrm{Ni}$. Whereas the predictions from Equation (3) were found at $9 \mathrm{Zr}, \mathbf{2 N i}, 3 \mathrm{Ni}, \mathbf{1 0 N i}$ and $\mathbf{1 1 N i}$. Therefore, by the intersection results of Equations (2) and (3), the new proposed catalysts for PE polymerization are $\mathbf{2 N i}, \mathbf{3 N i}$, and $\mathbf{1 0 N i}$ and they are expected to be potential catalysts with predicted PE catalytic activities (Equation (3)) of 47324, 37871, and 41383 $\mathrm{kg}(\mathrm{PE}) / \mathrm{mol}(\mathrm{Cat}.) \cdot \mathrm{MPa} \cdot \mathrm{h}$, respectively. When looking into the details of these proposed catalysts, our QSAR finding suggested that the higher HOMO energy level and the negative total charge of $\mathbf{R}_{3}$ substituents tend to increase the PE activity.

Table 5. Electronic descriptors and predicted activities from Equations (2) and (3) of newly designed FI-Zr and FI-Ni catalysts. The higher predicted activities of PE polymerization more than 35,000 $\mathrm{kg}(\mathrm{PE}) / \mathrm{mol}(\mathrm{Cat}.) \mathrm{MPa} \cdot \mathrm{h}$ are highlighted in red numbers.

\begin{tabular}{cccccccc}
\hline \multirow{2}{*}{ Complex } & \multicolumn{3}{c}{ Substituents } & \multicolumn{2}{c}{ Descriptors } & Predicted PE Activity ${ }^{\text {a }}$ \\
\cline { 2 - 8 } & $\mathbf{R 1}$ & R2 & R3 & R3-Charge & HOMO & \\
\hline & & & & & & Equation (2) & Equation (3) \\
\hline $2-Z r$ & $\mathrm{t}-\mathrm{Bu}$ & $\mathrm{H}$ & $m$-OAll & -1.115 & -0.199 & 12,260 & 11,474 \\
$3-\mathrm{Zr}$ & $\mathrm{t}-\mathrm{Bu}$ & $\mathrm{H}$ & $p$-OAll & -1.124 & -0.194 & 18,134 & 19,368 \\
$4-\mathrm{Zr}$ & $\mathrm{t}-\mathrm{Bu}$ & $\mathrm{Me}$ & $\mathrm{H}$ & 0.135 & -0.194 & 19,141 & 17,009 \\
$5-\mathrm{Zr}$ & $\mathrm{t}-\mathrm{Bu}$ & $\mathrm{Me}$ & $m$-OAll & -1.105 & -0.197 & 15,335 & 12,979 \\
\hline
\end{tabular}


Table 5. Cont.

\begin{tabular}{|c|c|c|c|c|c|c|c|}
\hline \multirow{2}{*}{ Complex } & \multicolumn{3}{|c|}{ Substituents } & \multicolumn{2}{|c|}{ Descriptors } & \multicolumn{2}{|c|}{ Predicted PE Activity $^{a}$} \\
\hline & R1 & $\mathbf{R 2}$ & R3 & R3-Charge & HOMO & & \\
\hline & & & & & & Equation (2) & Equation (3) \\
\hline $6-\mathrm{Zr}$ & $\mathrm{t}-\mathrm{Bu}$ & $\mathrm{Me}$ & $p$-OAll & -1.119 & -0.190 & 31,764 & 24,327 \\
\hline $7-\mathrm{Zr}$ & $\mathrm{t}-\mathrm{Bu}$ & $\mathrm{t}-\mathrm{Bu}$ & $\mathrm{H}$ & 0.135 & -0.198 & 43,697 & 32,147 \\
\hline $8-\mathrm{Zr}$ & $\mathrm{t}-\mathrm{Bu}$ & $\mathrm{t}-\mathrm{Bu}$ & $m$-OAll & -1.096 & -0.192 & 12,709 & 10,737 \\
\hline $9-\mathrm{Zr}$ & $\mathrm{t}-\mathrm{Bu}$ & $\mathrm{t}-\mathrm{Bu}$ & $p$-OAll & -1.117 & -0.189 & 30,879 & 36,923 \\
\hline $10-\mathrm{Zr}$ & Cumyl & $\mathrm{H}$ & $\mathrm{H}$ & 0.136 & -0.199 & 25,310 & 2709 \\
\hline $11-\mathrm{Zr}$ & Cumyl & $\mathrm{H}$ & m-OAll & -1.128 & -0.197 & 20,015 & 21,072 \\
\hline $12-\mathrm{Zr}$ & Cumyl & $\mathrm{H}$ & $p$-OAll & -1.124 & -0.191 & 17,239 & 19,574 \\
\hline $13-\mathrm{Zr}$ & Cumyl & $\mathrm{Me}$ & $\mathrm{H}$ & 0.134 & -0.191 & 33,901 & 21,331 \\
\hline $14-\mathrm{Zr}$ & Cumyl & $\mathrm{Me}$ & $m$-OAll & -1.123 & -0.193 & 17,624 & 18,965 \\
\hline $15-\mathrm{Zr}$ & Cumyl & $\mathrm{Me}$ & p-OAll & -1.116 & -0.187 & 30,705 & 31,103 \\
\hline $16-\mathrm{Zr}$ & Cumyl & Cumyl & $\mathrm{H}$ & 0.119 & -0.190 & 17,817 & 12,411 \\
\hline $17-\mathrm{Zr}$ & Cumyl & Cumyl & $m$-OAll & -1.096 & -0.189 & 24,490 & 24,515 \\
\hline $18-\mathrm{Zr}$ & Cumyl & Cumyl & $p$-OAll & -1.101 & -0.189 & 25,768 & 27,286 \\
\hline $2-\mathrm{Ni}$ & $\mathrm{t}-\mathrm{Bu}$ & $\mathrm{H}$ & $m$-OAll & -1.132 & -0.188 & 36,587 & 47,324 \\
\hline $3-\mathrm{Ni}$ & $\mathrm{t}-\mathrm{Bu}$ & $\mathrm{H}$ & $p$-OAll & -1.136 & -0.183 & 38,497 & 37,871 \\
\hline $4-\mathrm{Ni}$ & $\mathrm{t}-\mathrm{Bu}$ & $\mathrm{Me}$ & $\mathrm{H}$ & 0.138 & -0.183 & 40,245 & 28,649 \\
\hline $5-\mathrm{Ni}$ & $\mathrm{t}-\mathrm{Bu}$ & $\mathrm{Me}$ & $m$-OAll & -1.104 & -0.182 & 26,809 & 17,645 \\
\hline $6-\mathrm{Ni}$ & $\mathrm{t}-\mathrm{Bu}$ & $\mathrm{Me}$ & $p$-OAll & -1.135 & -0.177 & 37,849 & 22,786 \\
\hline 7-Ni & $\mathrm{t}-\mathrm{Bu}$ & $\mathrm{t}-\mathrm{Bu}$ & $\mathrm{H}$ & 0.138 & -0.183 & 40,245 & 27,974 \\
\hline $10-\mathrm{Ni}$ & $\mathrm{t}-\mathrm{Bu}$ & $\mathrm{t}-\mathrm{Bu}$ & $m$-OAll & -0.140 & -0.187 & 43,849 & 41,383 \\
\hline $11-\mathrm{Ni}$ & $\mathrm{t}-\mathrm{Bu}$ & $\mathrm{t}-\mathrm{Bu}$ & $p$-OAll & -1.126 & -0.186 & 34,187 & 35,222 \\
\hline $12-\mathrm{Ni}$ & Cumyl & $\mathrm{H}$ & $\mathrm{H}$ & -1.145 & -0.180 & 42,380 & 34,431 \\
\hline $13-\mathrm{Ni}$ & Cumyl & $\mathrm{H}$ & $m$-OAll & 0.137 & -0.179 & 38,555 & 21,053 \\
\hline $14-\mathrm{Ni}$ & Cumyl & $\mathrm{H}$ & $p$-OAll & -1.124 & -0.181 & 33,422 & 24,122 \\
\hline $15-\mathrm{Ni}$ & Cumyl & $\mathrm{Me}$ & $\mathrm{H}$ & -1.132 & -0.176 & 36,794 & 19,909 \\
\hline $16-\mathrm{Ni}$ & Cumyl & $\mathrm{Me}$ & $m$-OAll & 0.130 & -0.178 & 28,557 & 13,369 \\
\hline $17-\mathrm{Ni}$ & Cumyl & $\mathrm{Me}$ & $p$-OAll & -1.101 & -0.176 & 25,915 & 10,772 \\
\hline $18-\mathrm{Ni}$ & Cumyl & Cumyl & $\mathrm{H}$ & -1.098 & -0.178 & 25,050 & 11,616 \\
\hline
\end{tabular}

${ }^{a}$ in units of $\mathrm{kg}(\mathrm{PE}) / \mathrm{mol}($ Cat.) $\cdot \mathrm{MPa} \cdot \mathrm{h}$.

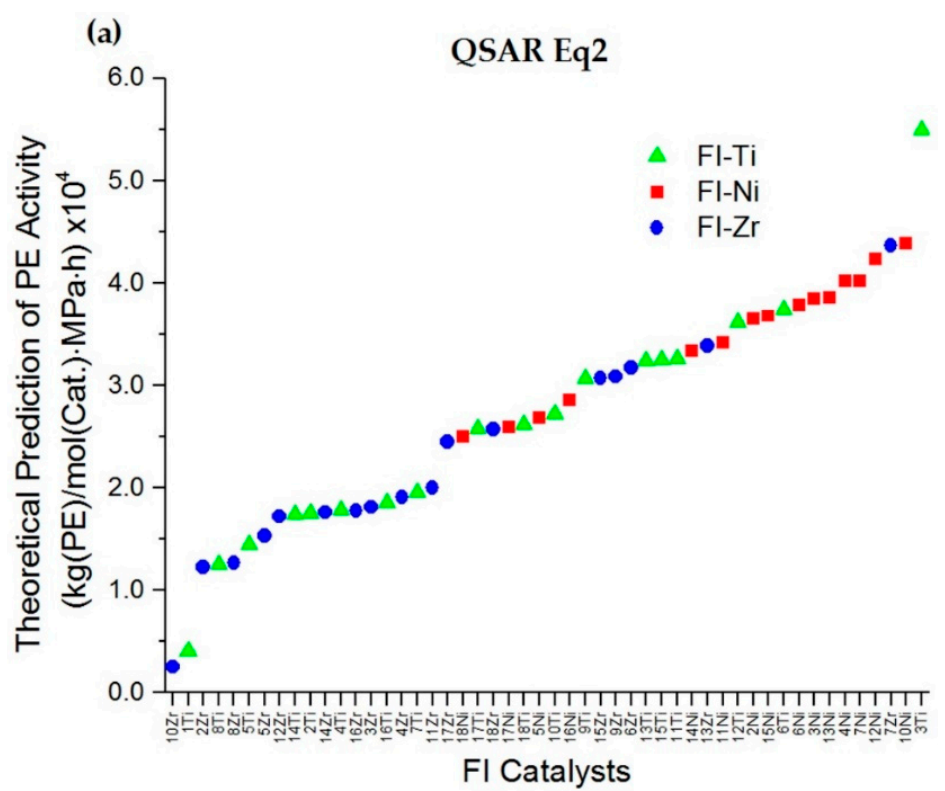

Figure 4. Cont. 


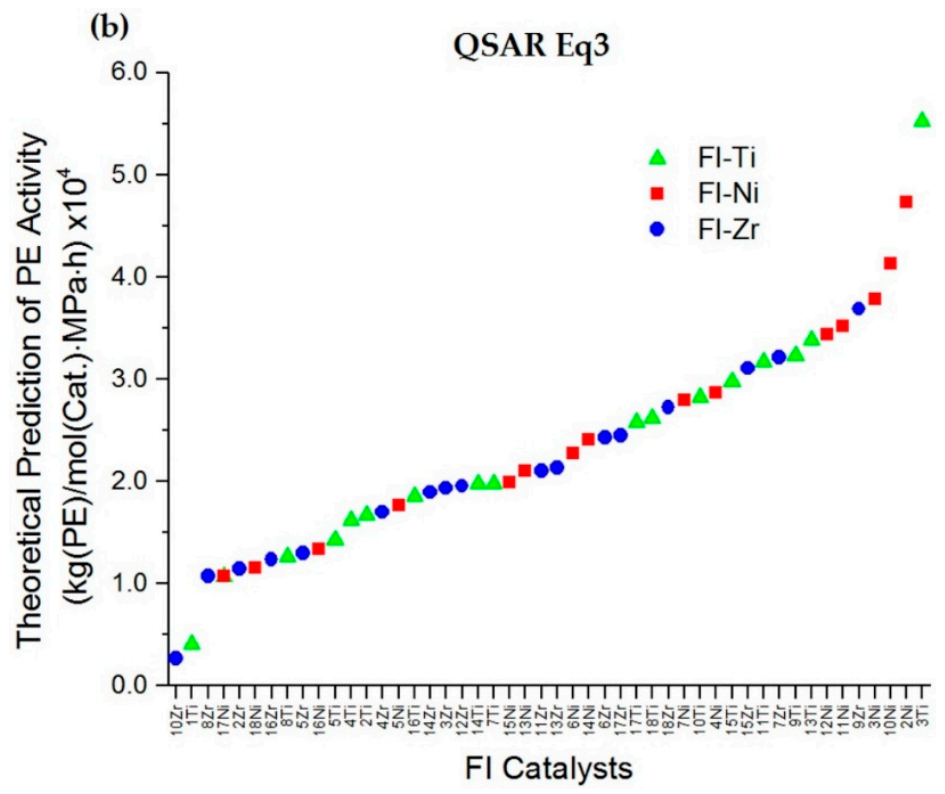

Figure 4. Trend of the predicted PE activity of all FI catalysts via Equation (2) (a) and Equation (3) (b).

\section{Materials and Methods}

\subsection{Source of Experimental Datasets}

For the experimental data of PE activity over the FI-Ti catalysts, the time-averaged activity of the FI-Ti catalysts in ethylene polymerization is defined as:

$$
\text { activity }=\frac{M_{C_{2} H_{4}} \int_{0}^{\tau} W_{p}(t) d t}{C_{T i} p_{C_{2} H_{4}} \tau}
$$

where $M_{\left(C_{2} \mathrm{H}_{4}\right)}$ and $p_{\left(\mathrm{C}_{2} \mathrm{H}_{4}\right)}$ denote the molecular weight and the pressure of ethylene, respectively; $C_{T i}$ is the initial concentration of a catalyst, $\tau$ is polymerization time, and $W_{p}(t)$ is the propagation rate given by:

$$
W_{p}=k_{e f f}[T i]_{a c t}\left[C_{2} H_{4}\right]
$$

where $k_{e f f}$ is the effective rate constant (activity of a single active site) and [Ti] $]_{a c t}$ and $\left[\mathrm{C}_{2} \mathrm{H}_{4}\right]$ denote the concentrations of active sites and ethylene, respectively. For the QSAR study, the assumption of the same conditions for obtaining PE polymerization activity is required; thus, the catalytic activity should be determined by a composite function of $k_{\text {eff }}[\text { Ti }]_{a c t}$, as reported by Nikitin et al. [35]. The FI-Ti catalytic activities for $\mathrm{PE}$ polymerization were given in $\mathrm{kg}(\mathrm{PE}) / \mathrm{mol}(\mathrm{Cat}.) \cdot \mathrm{MPa} \cdot \mathrm{h}$ units, and the temperature conditions were chosen at $40{ }^{\circ} \mathrm{C}$ except $1 \mathrm{Ti}, 4 \mathrm{Ti}, 7 \mathrm{Ti}, 10 \mathrm{Ti}, 13 \mathrm{Ti}$ and $16 \mathrm{Ti}$, which were estimated by their $40{ }^{\circ} \mathrm{C}$ performance condition by (activity $\left.\left(30^{\circ} \mathrm{C}\right)+\operatorname{activity}\left(50{ }^{\circ} \mathrm{C}\right)\right) / 2$. Therefore, the FI-Ti catalytic activities for PE polymerization in this work were collected from Nikitin's work and they are listed in Table 1.

\subsection{Structural Optimization}

All the calculations were performed with the M06L density functional method using the Gaussian 09 software package (Gaussian, Inc., Wallingford, CT, USA, 2009) [60]. The 6-31G** basis set was used for $\mathrm{C}, \mathrm{O}, \mathrm{N}, \mathrm{H}$, and $\mathrm{Cl}$, while LANL2DZ was used for $\mathrm{Ti}, \mathrm{Zr}$, and Ni. The structures of the metal complexes were optimized and their energies were calculated to extract electronic and steric properties. Ten electronic properties were collected: the charges of metal centers with $\mathrm{Ti} / \mathrm{Zr} / \mathrm{Ni}$ atoms, the average charge of $\mathrm{O}, \mathrm{N}$, and $\mathrm{Cl}$, charges of substitution groups on phenoxy-imine ligands of $\mathbf{R}_{\mathbf{1}}, \mathbf{R}_{\mathbf{2}}$, and $\mathbf{R}_{\mathbf{3}}$, $\mathrm{HOMO}$ energy, LUMO energy, and bond distances of metal centers to surrounding $\mathrm{O}, \mathrm{N}$, and $\mathrm{Cl}$ atoms. 


\subsection{QSAR Model}

In QSAR studies, the choices of descriptors are the important steps to achieve the model with high correlation and prediction ability [61]. Hence, the GA method as an effective technique to select the appropriate variables was used in this work. Catalytic activity was defined as the dependent variable, and there were a total of 10 molecular electronic properties (descriptors), including atomistic charges and quantum-chemical descriptors, which were fitted via the leave-one-out cross-validation coefficient value as a fitness function. The genetic function approximation (GFA) algorithm implemented in the Materials Studio 7.0 package (Accelrys Software Inc., San Diego, CA, USA, 2013) was used to construct the QSAR models [62].

\subsection{Statistical Terms}

$R^{2}$ is the fraction of the total variance of the $Y$ variable $(\ln (A))$ that is explained by the genetic function approximation equation. $R^{2}$ is calculated as:

$$
\frac{\mathrm{SSR}}{\mathrm{SST}}
$$

where SSR is the sum of squares of regression and SST is the total sum of squares. Generally, the closer the value is to 1.0, the better the genetic function approximation equation explains the $Y$ variable.

$\mathrm{R}^{2}{ }_{\mathrm{cv}}$ is derived from cross validation process, in this work, we used the leave-one-out validation. The $\mathrm{R}_{\mathrm{cv}}$ is calculated as follows:

$$
1-\frac{\text { PRESS }}{\text { SST }}
$$

where PRESS is the predictive sum of squares of a model. The $\mathrm{R}^{2} \mathrm{cv}$ represents the predictive power of a model for further prediction on some new catalysts. For a good model, $R^{2}{ }_{c v}$ should be close to $R^{2}$.

The following is used for the F test:

$$
\frac{\operatorname{SSR} /(p-1)}{\operatorname{SSE} /(n-p)}
$$

where SSE is the sum of squares of errors. This is the sum of squared differences between measurements, and model predictions over the entire data set. SSR is the sum of squares due to regression. $n$ and $p$ represent the number of data points and the number of parameters in a regression model, respectively. Thus, the ratio $\mathrm{F}=\{\mathrm{SSR} /(p-1)\} /\{\mathrm{SSE} /(n-p)\}$ is then calculated and compared with the tabulated values of the $\mathrm{F}$ distribution for different values of $n$ and $p$. The $\mathrm{F}$ value is derived from the $\mathrm{F}$ test, indicating the probability of a true relationship, or the significance level of the QSAR model. The $\mathrm{F}$ value is the ratio between explained and unexplained variance for a given number of degrees of freedom. Therefore, the larger the F value, the greater the probability that the QSAR equation is significant [62-64].

\section{Conclusions}

The phenoxy-imine catalysts were tailored by varying the substituent groups on the ligand units and also the metal center. Their activities were then calculated via DFT. After analyzing the raw data of the DFT simulations and experimental values of FI-Ti with the QSAR method, the calculated properties from DFT illustrated the significant relation between realistic catalytic activity and the calculated electronic descriptors. For the best obtained QSAR models, consisting of two models of Equations (2) and (3), their $R^{2}$ and $R^{2}{ }_{c v}$ values are greater than 0.927. From insight into the QSAR models, the HOMO energy level and the total charge of $\mathbf{R}_{3}$ substituent electronic properties could be used to predict the PE activity of the FI-Ti catalysts. The design concept of "head-hat" was applied by replacing the head of Ti metal by Zr or Ni metals, where the hats were still kept as phenoxy-imine substituents. Based on the obtained QSAR models derived from the FI-Ti training set, the PE polymerization 
activities of the new metallocene catalysts of the FI-Zr and FI-Ni series were then predicted using QSAR Equations (2) and (3). To purpose the candidate catalysts, higher PE polymerization activities than $35,000 \mathrm{~kg}(\mathrm{PE}) / \mathrm{mol}(\mathrm{Cat}.) \cdot \mathrm{MPa} \cdot \mathrm{h}$ on those QSAR models were considered, and it was found that based on all metallocene complexes that consist of $\mathrm{Ni}$ as a metal center atom showed better $\mathrm{PE}$ performance than that of the Ti and $\mathrm{Zr}$ metal center pheoxy-imines. Thus, the new purposed catalysts for PE polymerization are $\mathbf{2} \mathbf{N i}, \mathbf{3 N i}$ and $\mathbf{1 0 N i}$ metallocene complexes. The present work shows that the combined DFT and QSAR studies are straightforward methods to derive the relationship between PE catalytic activity and electronic descriptors, and the obtained QSAR model could be used for evaluating and designing new catalyst structures in search of promising polyethylene catalysts. This tailor-made study is beneficial to industrial research, and it is a simple method.

Author Contributions: Visualization and Simulations, P.C.; Conceptualization, P.M. and V.P.; Formal analysis, P.M., V.P., D.Z., and L.S.; Writing-original draft, P.C., H.W. and P.M.

Funding: Thailand Research Fund (RTA6080005).

Acknowledgments: This work was supported by Vidyasirimedhi Institute of Science and Technology (VISTEC) for both funds and equipment. Thanks goes to support from the Thailand Research Fund (RTA6080005) and Research Center of Nano Science and Technology, Shanghai University. We would like to thank NANOTEC, Thailand Sci Park for cluster computer and software supports. PM and LS would like to thank the Shanghai Municipal Science and Technology Commission of Professional and Technical Service Platform for Designing and Manufacturing of Advanced Composite Materials (16DZ2292100).

Conflicts of Interest: The authors declare no conflict of interest.

\section{References}

1. Xie, H.; Hua, X.; Liu, B.; Wu, C.; Cui, D. Phosphinimino-amino supported complex: Synthesis, polymerization of ethylene and dearomatisation of pyridine. J. Organomet. Chem. 2015, 798, 335-340. [CrossRef]

2. Nyamato, G.S.; Ojwach, S.O.; Akerman, M.P. Ethylene oligomerization studies by nickel(II) complexes chelated by (amino)pyridine ligands: Experimental and density functional theory studies. Dalton Trans. 2016, 45, 3407-3416. [CrossRef] [PubMed]

3. Cai, Z.; Do, L.H. Customizing polyolefin morphology by selective pairing of alkali ions with nickel phenoxyimine-polyethylene glycol catalysts. Organometallics 2017, 36, 4691-4698. [CrossRef]

4. Yu, F.; Yang, Y.; He, D.; Gong, D.; Chen, Z.-R. Pressure-sensitive supported FI catalyst for the precise synthesis of uni- and bimodal polyethylene. Ind. Eng. Chem. Res. 2017, 56, 4684-4689. [CrossRef]

5. Goerl, C.; Betthausen, E.; Alt, H.G. Di- and trinuclear iron/titanium and iron/zirconium complexes with heterocyclic ligands as catalysts for ethylene polymerization. Polyhedron 2016, 118, 37-51. [CrossRef]

6. Woo, J.O.; Kang, S.K.; Park, J.-E.; Son, K.-S. Synthesis, characterization, and ethylene polymerization behavior of cr(III) catalysts based on bis(pyrazolylmethyl)pyridine and its derivatives. J. Mol. Catal. A Chem. 2015, 404-405, 204-210. [CrossRef]

7. Steelman, D.K.; Xiong, S.; Pletcher, P.D.; Smith, E.; Switzer, J.M.; Medvedev, G.A.; Delgass, W.N.; Caruthers, J.M.; Abu-Omar, M.M. Effects of pendant ligand binding affinity on chain transfer for 1-hexene polymerization catalyzed by single-site zirconium amine bis-phenolate complexes. J. Am. Chem. Soc. 2013, 135, 6280-6288. [CrossRef] [PubMed]

8. Martínez, S.; Cruz, V.L.; Ramos, J.; Martínez-Salazar, J. Polymerization activity prediction of zirconocene single-site catalysts using 3d quantitative structure-activity relationship modeling. Organometallics 2012, 31, 1673-1679. [CrossRef]

9. Kim, S.; Park, J.; Song, B.; Yoon, S.-W.; Go, M.; Lee, J.; Lee, B. Preparation of thiophene-fused and tetrahydroquinoline-linked cyclopentadienyl titanium complexes for ethylene/ $\alpha$-olefin copolymerization. Catalysts 2013, 3, 104. [CrossRef]

10. Shamiri, A.; Chakrabarti, M.; Jahan, S.; Hussain, M.; Kaminsky, W.; Aravind, P.; Yehye, W. The influence of ziegler-natta and metallocene catalysts on polyolefin structure, properties, and processing ability. Materials 2014, 7, 5069. [CrossRef] [PubMed]

11. Alt, H.G.; Köppl, A. Effect of the nature of metallocene complexes of group iv metals on their performance in catalytic ethylene and propylene polymerization. Chem. Rev. 2000, 100, 1205-1222. [CrossRef] [PubMed] 
12. Luo, W.; Li, A.; Liu, S.; Ye, H.; Li, Z. 2-benzimidazol-6-pyrazol-pyridine chromium(III) trichlorides: Synthesis, characterization, and application for ethylene oligomerization and polymerization. Organometallics 2016, 35, 3045-3050. [CrossRef]

13. Bariashir, C.; Wang, Z.; Du, S.; Solan, G.A.; Huang, C.; Liang, T.; Sun, W.-H. Cycloheptyl-fused nno-ligands as electronically modifiable supports for $\mathrm{M}(\mathrm{II})(\mathrm{M}=\mathrm{Co}, \mathrm{Fe})$ chloride precatalysts; probing performance in ethylene oligo-/polymerization. J. Polym. Sci. Part A Polym. Chem. 2017, 55, 3980-3989. [CrossRef]

14. Du, S.; Wang, X.; Zhang, W.; Flisak, Z.; Sun, Y.; Sun, W.-H. A practical ethylene polymerization for vinyl-polyethylenes: Synthesis, characterization and catalytic behavior of $\alpha, \alpha^{\prime}$-bisimino-2,3:5,6-bis (pentamethylene)pyridyliron chlorides. Polym. Chem. 2016, 7, 4188-4197. [CrossRef]

15. Park, J.-E.; Kang, S.K.; Woo, J.O.; Son, K.-S. Highly active chromium(III) complexes based on tridentate pyrazolyl pyridyl ligands for ethylene polymerization and oligomerization. Dalton Trans. 2015, 44, 9964-9969. [CrossRef] [PubMed]

16. Nyamato, G.S.; Alam, M.G.; Ojwach, S.O.; Akerman, M.P. (pyrazolyl)-(phosphinoyl)pyridine iron(II), cobalt(II) and nickel(II) complexes: Synthesis, characterization and ethylene oligomerization studies. J. Organomet. Chem. 2015, 783, 64-72. [CrossRef]

17. Falivene, L.; Cavallo, L.; Talarico, G. Buried volume analysis for propene polymerization catalysis promoted by group 4 metals: A tool for molecular mass prediction. ACS Catal. 2015, 5, 6815-6822. [CrossRef]

18. Nomura, K.; Mitsudome, T.; Igarashi, A.; Nagai, G.; Tsutsumi, K.; Ina, T.; Omiya, T.; Takaya, H.; Yamazoe, S. Synthesis of (adamantylimido)vanadium(V) dimethyl complex containing (2-anilidomethyl)pyridine ligand and selected reactions: Exploring the oxidation state of the catalytically active species in ethylene dimerization. Organometallics 2017, 36, 530-542. [CrossRef]

19. Makio, H.; Terao, H.; Iwashita, A.; Fujita, T. Fi catalysts for olefin polymerization-A comprehensive treatment. Chem. Rev. 2011, 111, 2363-2449. [CrossRef] [PubMed]

20. Mitani, M.; Furuyama, R.; Mohri, J.-I.; Saito, J.; Ishii, S.; Terao, H.; Nakano, T.; Tanaka, H.; Fujita, T. Syndiospecific living propylene polymerization catalyzed by titanium complexes having fluorine-containing phenoxy-imine chelate ligands. J. Am. Chem. Soc. 2003, 125, 4293-4305. [CrossRef] [PubMed]

21. Mitani, M.; Mohri, J.-I.; Yoshida, Y.; Saito, J.; Ishii, S.; Tsuru, K.; Matsui, S.; Furuyama, R.; Nakano, T.; Tanaka, H.; et al. Living polymerization of ethylene catalyzed by titanium complexes having fluorine-containing phenoxy-imine chelate ligands. J. Am. Chem. Soc. 2002, 124, 3327-3336. [CrossRef] [PubMed]

22. Saito, J.; Mitani, M.; Matsui, S.; Tohi, Y.; Makio, H.; Nakano, T.; Tanaka, H.; Kashiwa, N.; Fujita, T. A new titanium complex having two phenoxy-imine chelate ligands for ethylene polymerization. Macromol. Chem. Phys. 2002, 203, 59-65. [CrossRef]

23. Terao, H.; Ishii, S.; Mitani, M.; Tanaka, H.; Fujita, T. Ethylene/polar monomer copolymerization behavior of bis(phenoxy-imine)ti complexes: Formation of polar monomer copolymers. J. Am. Chem. Soc. 2008, 130, 17636-17637. [CrossRef] [PubMed]

24. Makio, H.; Kashiwa, N.; Fujita, T. Fi catalysts: A new family of high performance catalysts for olefin polymerization. Adv. Synth. Catal. 2002, 344, 477-493. [CrossRef]

25. Wang, Z.; Solan, G.A.; Mahmood, Q.; Liu, Q.; Ma, Y.; Hao, X.; Sun, W.-H. Bis(imino)pyridines incorporating doubly fused eight-membered rings as conformationally flexible supports for cobalt ethylene polymerization catalysts. Organometallics 2018, 37, 380-389. [CrossRef]

26. Ishii, S.; Nakano, T.; Kawamura, K.; Kinoshita, S.; Ichikawa, S.; Fujita, T. Development of new selective ethylene trimerization catalysts based on highly active ethylene polymerization catalysts. Catal. Today 2018, 303, 263-270. [CrossRef]

27. Wang, Z.; Liu, Q.; Solan, G.A.; Sun, W.-H. Recent advances in ni-mediated ethylene chain growth: Nimine-donor ligand effects on catalytic activity, thermal stability and oligo-/polymer structure. Coord. Chem. Rev. 2017, 350, 68-83. [CrossRef]

28. Preston, A.Z.; Kim, J.; Medvedev, G.A.; Delgass, W.N.; Caruthers, J.M.; Abu-Omar, M.M. Steric and solvation effects on polymerization kinetics, dormancy, and tacticity of Zr-salan catalysts. Organometallics 2017, 36, 2237-2244. [CrossRef]

29. Mitchell, N.E.; Anderson, W.C., Jr.; Long, B.K. Mitigating chain-transfer and enhancing the thermal stability of co-based olefin polymerization catalysts through sterically demanding ligands. J. Polym. Sci. Part A. Polym. Chem. 2017, 55, 3990-3995. [CrossRef] 
30. D'Auria, I.; Milione, S.; Caruso, T.; Balducci, G.; Pellecchia, C. Synthesis of hyperbranched low molecular weight polyethylene oils by an iminopyridine nickel(II) catalyst. Polym. Chem. 2017, 8, 6443-6454. [CrossRef]

31. Tuskaev, V.A.; Gagieva, S.C.; Kurmaev, D.A.; Kolosov, N.A.; Fedyanin, I.V.; Bulychev, B.M. Titanium (IV) complexes stabilized by 2,6-bis-( $\alpha, \alpha^{\prime}$-diphenyl(hydroxy)methyl)-pyridine: Catalytic activity in olefin polymerization and impact of lithium and magnesium chlorides. Inorg. Chim. Acta 2015, 425, 275-281. [CrossRef]

32. Ratanasak, M.; Rungrotmongkol, T.; Saengsawang, O.; Hannongbua, S.; Parasuk, V. Towards the design of new electron donors for ziegler-natta catalyzed propylene polymerization using qspr modeling. Polymer 2015, 56, 340-345. [CrossRef]

33. Ratanasak, M.; Parasuk, V. Roles of malonate donor on activity and stereoselectivity of ziegler-natta catalyzed propylene polymerization. J. Organomet. Chem. 2015, 775, 6-11. [CrossRef]

34. Nyamato, G.S.; Ojwach, S.O.; Akerman, M.P. Potential hemilabile (imino)pyridine palladium(II) complexes as selective ethylene dimerization catalysts: An experimental and theoretical approach. Organometallics 2015, 34, 5647-5657. [CrossRef]

35. Nikitin, S.V.; Nikitin, V.V.; Oleynik, I.I.; Oleynik, I.V.; Bagryanskaya, E.G. Activity of phenoxy-imine titanium catalysts in ethylene polymerization: A quantum chemical approach. J. Mol. Catal. A Chem. 2016, 423, 285-292. [CrossRef]

36. Yang, W.; Yi, J.; Ma, Z.; Sun, W.-H. 2d-qsar modeling on the catalytic activities of 2-azacyclyl6-aryliminopyridylmetal precatalysts in ethylene oligomerization. Catal. Commun. 2017, 101, 40-43. [CrossRef]

37. Manz, T.A. Deactivation of $\mathrm{Ti}$ and $\mathrm{Zr}$ half-metallocene complexes activated with $\mathrm{B}\left(\mathrm{C}_{6} \mathrm{~F}_{5}\right)_{3}$ : A case study in constructing DFT-based qsars to predict unimolecular rate constants. RSC Adv. 2015, 5, 48246-48254. [CrossRef]

38. Cruz, V.L.; Martinez, S.; Ramos, J.; Martinez-Salazar, J. 3D-QSAR as a tool for understanding and improving single-site polymerization catalysts. Organometallics 2014, 33, 2944-2959. [CrossRef]

39. Cruz, V.L.; Martinez, S.; Martinez-Salazar, J.; Polo-Cerón, D.; Gómez-Ruiz, S.; Fajardo, M.; Prashar, S. 3D-QSAR study of ANSA-metallocene catalytic behavior in ethylene polymerization. Polymer 2007, 48, 4663-4674. [CrossRef]

40. Melanie, M. Genetic algorithms: An overview. Complexity 1995, 1, 31-39.

41. McCall, J. Genetic algorithms for modelling and optimisation. J. Comput. Appl. Math. 2005, 184, $205-222$. [CrossRef]

42. Fisz, J.J. Combined genetic algorithm and multiple linear regression (GA-MLR) optimizer: Application to multi-exponential fluorescence decay surface. J. Phys. Chem. A 2006, 110, 12977-12985. [CrossRef] [PubMed]

43. Rogers, D.; Hopfinger, A.J. Application of genetic function approximation to quantitative structure-activity relationships and quantitative structure-property relationships. J. Chem. Inf. Comp. Sci. 1994, 34, 854-866. [CrossRef]

44. Zhao, Y.; Truhlar, D.G. A new local density functional for main-group thermochemistry, transition metal bonding, thermochemical kinetics, and noncovalent interactions. J. Chem. Phys. 2006, 125, 194101. [CrossRef] [PubMed]

45. Della Sala, F.; Fabiano, E.; Constantin, L.A. Kinetic-energy-density dependent semilocal exchange-correlation functionals. Int. J. Quantum Chem. 2016, 116, 1641-1694. [CrossRef]

46. Zhao, Y.; Truhlar, D.G. The m06 suite of density functionals for main group thermochemistry, thermochemical kinetics, noncovalent interactions, excited states, and transition elements: Two new functionals and systematic testing of four m06-class functionals and 12 other functionals. Theor. Chem. Acc. 2008, 120, 215-241.

47. Remya, K.; Suresh, C.H. Which density functional is close to ccsd accuracy to describe geometry and interaction energy of small noncovalent dimers? A benchmark study using gaussian09. J. Comput. Chem. 2013, 34, 1341-1353. [CrossRef] [PubMed]

48. Rakhi, R.; Suresh, C.H. A dft study on dihydropyrazine annulated linear polyacenes: Aromaticity, stability and homo-lumo energy modulation. PCCP 2016, 18, 24631-24641. [CrossRef] [PubMed]

49. Ahmad, S.; Gromiha, M.M. Design and training of a neural network for predicting the solvent accessibility of proteins. J. Comput. Chem. 2003, 24, 1313-1320. [CrossRef] [PubMed]

50. Hunger, J.; Huttner, G. Optimization and analysis of force field parameters by combination of genetic algorithms and neural networks. J. Comput. Chem. 1999, 20, 455-471. [CrossRef] 
51. Waller, C.L.; Bradley, M.P. Development and validation of a novel variable selection technique with application to multidimensional quantitative structure-activity relationship studies. J. Chem. Inf. Comp. Sci. 1999, 39, 345-355. [CrossRef]

52. Aires-de-Sousa, J.; Hemmer, M.C.; Gasteiger, J. Prediction of ${ }^{1} \mathrm{H}$ NMR chemical shifts using neural networks. Anal. Chem. 2002, 74, 80-90. [CrossRef] [PubMed]

53. Thakur, P.; Srivastava, D.C.; Gupta, P.K. The genetic algorithm: A robust method for stress inversion. J. Struct. Geol. 2017, 94, 227-239. [CrossRef]

54. Douguet, D.; Thoreau, E.; Grassy, G. A genetic algorithm for the automated generation of small organic molecules: Drug design using an evolutionary algorithm. J. Comput. Aided Mol. Des. 2000, 14, 449-466. [CrossRef] [PubMed]

55. Kubiny, H. Variable selection in QSAR studies. I. An evolutionary algorithm. Quant. Struct. Act. Relat. 1994, 13, 285-294. [CrossRef]

56. Leardi, R. 3-genetic algorithms in feature selection. In Genetic Algorithms in Molecular Modeling; Devillers, J., Ed.; Academic Press: Cambridge, MA, USA, 1996; pp. 67-86.

57. Wold, S.; Eriksson, L.; Clementi, S. Statistical validation of QSAR results. In Chemometric Methods in Molecular Design; VCH, P.O. Box: Weinheim, Germany, 2008; pp. 309-338.

58. Balakrishnan, N.; Colton, T.; Everitt, B.; Piegorsch, W.; Ruggeri, F.; Teugels, J.L. Ramp function. Wiley StatsRef Stat. Ref. Online 2014. [CrossRef]

59. Mudelsee, M. Ramp function regression: A tool for quantifying climate transitions. Comput. Geosci. 2000, 26, 293-307. [CrossRef]

60. Frisch, M.J.; Trucks, G.W.; Schlegel, H.B.; Scuseria, G.E.; Robb, M.A.; Cheeseman, J.R.; Scalmani, G.; Barone, V.; Petersson, G.A.; Nakatsuji, H.; et al. Gaussian 09, revision B.01; Gaussian Inc.: Wallingford UK, 2009.

61. Pourbasheer, E.; Aalizadeh, R.; Ganjali, M.R.; Norouzi, P.; Shadmanesh, J. QSAR study of ACK1 inhibitors by genetic algorithm-multiple linear regression (GA-MLR). J. Saudi Chem. Soc. 2014, 18, 681-688. [CrossRef]

62. Materials Studio Modeling; release 7.0; Accelrys Software Inc.: San Diego, CA, USA, 2013.

63. Smith, H.J.; Williams, H. Introduction to the Principles of Drug Design, 2nd ed.; The stonebrige press: Butterworth, Malaysian, 1988; pp. 240-264.

64. Leardi, R. Genetic algorithms in chemometrics and chemistry: A review. J. Chemom. 2001, 15, 559-569. [CrossRef] 